\title{
Spontaneous regression in advanced non-small cell lung cancer
}

\author{
Adam Gladwish, ${ }^{1}$ Katy Clarke, ${ }^{2}$ Andrea Bezjak ${ }^{2}$ \\ ${ }^{1}$ University of Toronto, Toronto, Ontario, Canada; \\ ${ }^{2}$ Radiation Oncology, Princess Margaret Hospital, Toronto, Ontario, Canada
}

Correspondence to Adam Gladwish, adam.gladwish@utoronto.ca

\section{SUMMARY}

Locally advanced lung cancer, if untreated, typically progresses although the rapidity of progression may vary. The authors report the case of an 84-year-old woman who presented with radiologically progressive, biopsy proven stage IIIB (T2N3) squamous cell carcinoma in the left lower lobe of the lung. Her disease was too advanced for curative treatment and in view of the lack of symptoms to palliate, she received no anticancer treatment. In follow-up, her tumour was noted to spontaneously regress in size on serial chest x-rays. Eight months after biopsy, restaging CT showed complete resolution of the enlarged biopsy proven mediastinal and hilar lymph nodes and significant regression of the primary tumour. She remains clinically well.

\section{BACKGROUND}

Lung cancer is currently the most common cause of cancer mortality worldwide. It accounted for 1.3 million deaths around the world (2.3\% of all deaths) in $2004 .{ }^{1}$ A direct link to tobacco use was noted in the 1950s by Doll and Hill and although tobacco use is decreasing, lung cancer remains a major public health issue. ${ }^{2}$ It has one of the lowest survival outcomes of any cancer, with an overall 5 -year survival of just $14 \%$. Stage specific 5 -year survival has been reported to be $42 \%$ for stage 1 non-small cell lung cancer (NSCLC) (15\% of patients at diagnosis) decreasing to $<5 \%$ in stage IV. Median survival of stage IIIB NSCLC is $8-13$ months $^{3}$ and 5 -year survival is between $3 \%$ and $7 \% .{ }^{4}$ Squamous cell carcinoma accounts for $25-30 \%$ of all lung cancers. ${ }^{3}$

Spontaneous regression of cancer is a rare event in general, with incidence estimated to be $<0.001 \%$ and less than 10 such cases of advanced NSCLC have been reported in

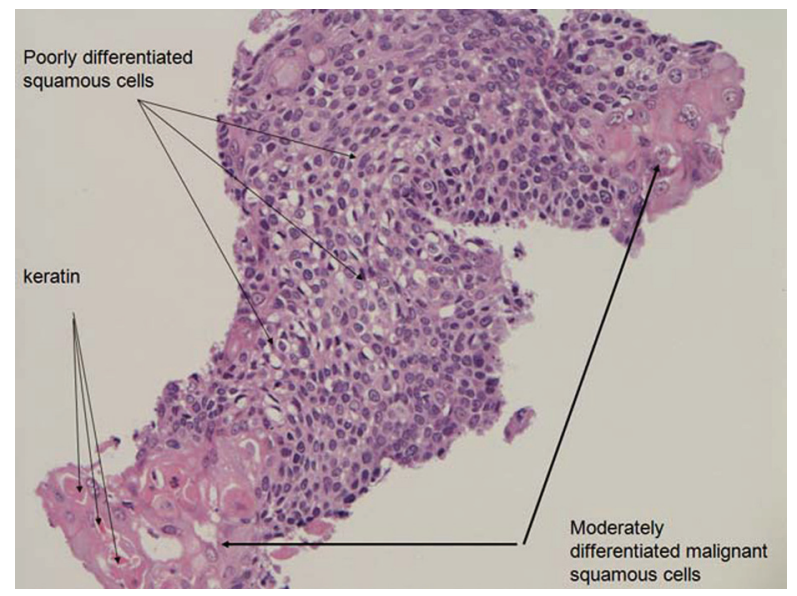

Figure 1 Tissue obtained via ultrasound-guided biopsy in February 2009 showing squamous cell carcinoma in the left lower lobe. the past 60 years. ${ }^{5}$ We present a rare and interesting case of a patient with stage IIIB biopsy proven squamous cell lung cancer whose tumour has spontaneously regressed with no active medical or surgical treatment.

\section{CASE PRESENTATION}

A fit 81-year-old woman initially presented to her family physician with small volume haemoptysis in November 2006. Work-up revealed a $14 \mathrm{~mm}$ spiculated nodule in the left lower lobe of the lung abutting the oblique fissure, with no evidence of lymphadenopathy or other abnormality on CT. Her haemoptysis resolved with no treatment. She had a 35 pack-year history of smoking, and a medical history significant only for dyslipidaemia, osteoarthritis and medically managed hypothyroidism. Her medications

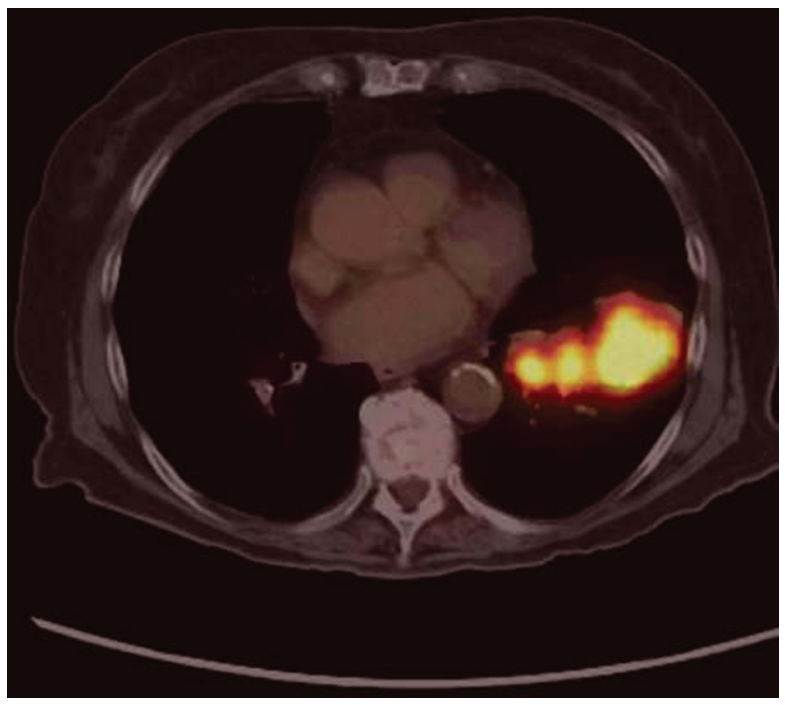

Figure 2 Fluorodeoxyglucose positron emission tomography CT scan from March 2009, showing the area of maximal standard uptake value within the left lower lobe. 


\section{BMJ Case Reports}

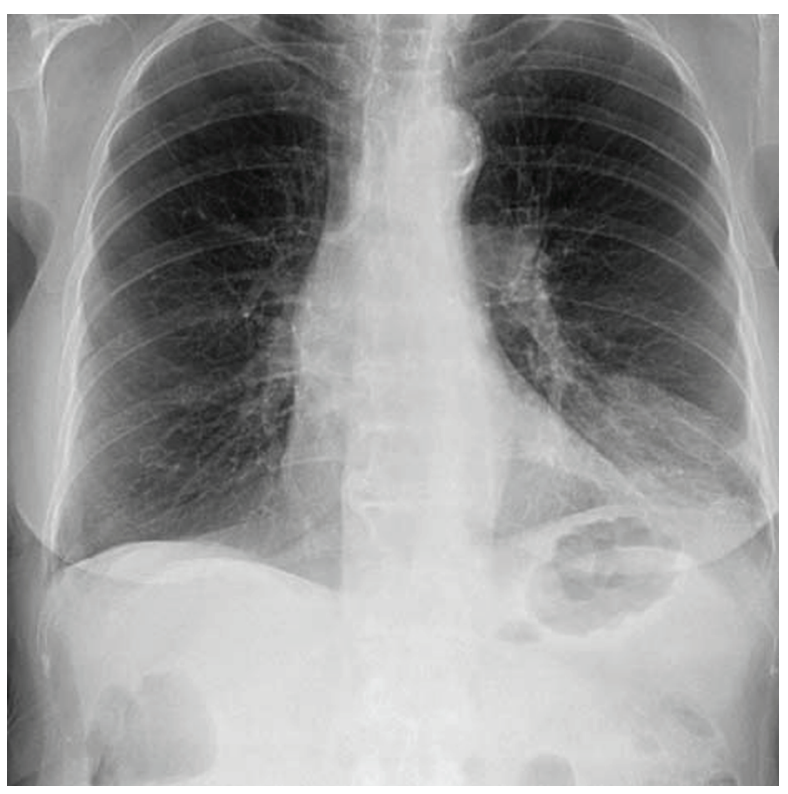

Figure 3 Chest x-ray from April 2009.

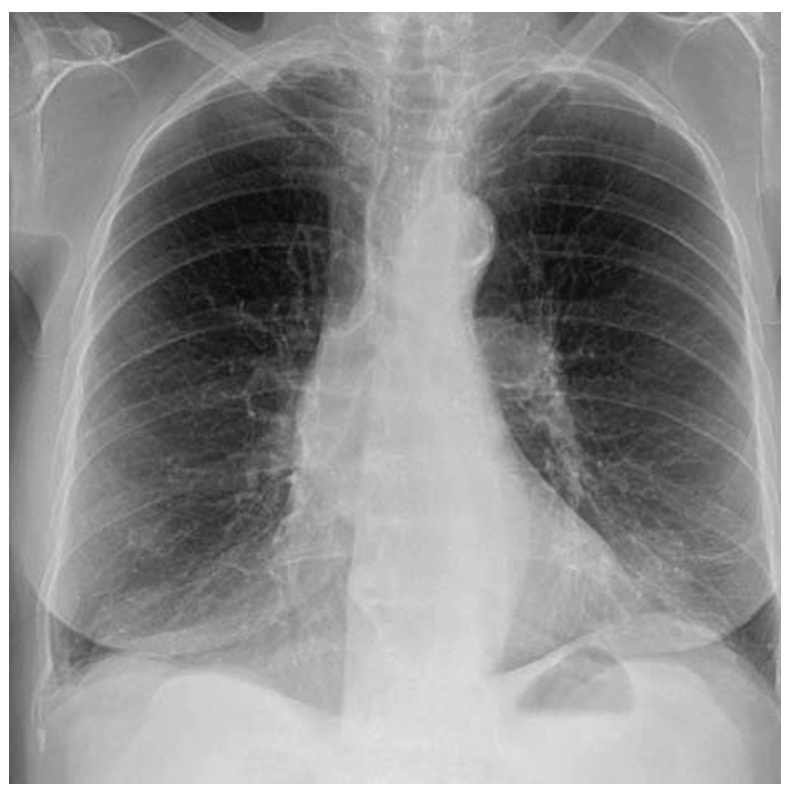

Figure 5 Chest x-ray from September 2009.

included Lipitor, aspirin, L-thyroxine, cholestyramine and glucosamine.

\section{INVESTIGATIONS}

CT guided biopsy of the left lower lobe lung lesion done in January 2007 showed no abnormal cells. As the lesion was small, active surveillance with interval imaging was recommended. Her initial restaging CTs in April 2007 and December 2007 showed no change in the size of the lesion. However, in June 2008, 18 months after initial diagnosis, there was a slight increase to $16 \mathrm{~mm}$ with note of a surrounding nodule measuring up to 9 $\mathrm{mm}$. As she remained very well and asymptomatic the patient declined biopsy at the time. CT was repeated in January 2009 and it revealed significant progression with

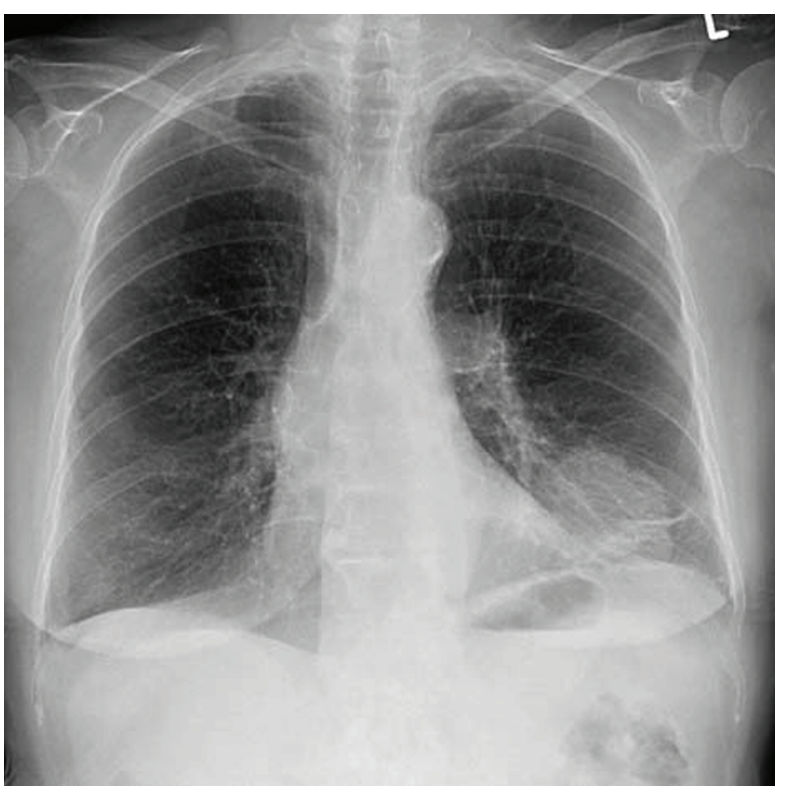

Figure 4 Chest x-ray from June 2009.

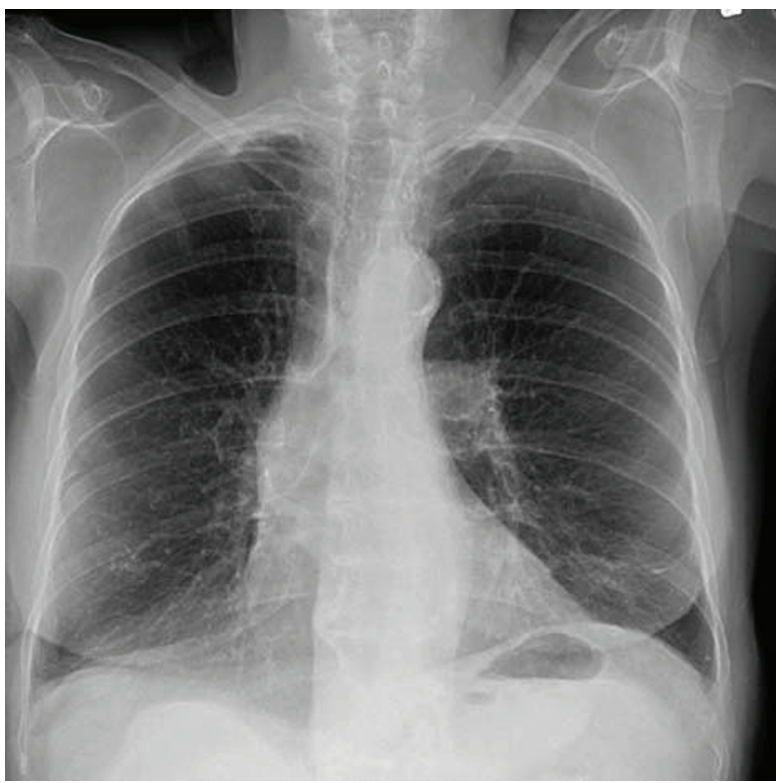

Figure 6 Chest x-ray from March 2010.

an increase in the main lesion to $3.9 \times 3.3 \mathrm{~cm}$, contiguous with a $2 \mathrm{~cm}$ satellite lesion. A $2.5 \mathrm{~cm}$ left hilar lymph node was noted. An ultrasound-guided biopsy of the left lower lobe lesion in February 2009 revealed a moderately differentiated squamous cell carcinoma (figure 1). Fluorodeoxyglucose positron emission tomography (FDG PET)-CT imaging in March 2009 revealed significant uptake within both left lower lobe lesions with a maximal standard uptake value (SUV) of 11.5 in the primary lesion, 9 in the satellite lesion and 8.5 in the left hilar lymph node (figure 2). SUV was also noted within the left and right lower paratracheal mediastinal lymph nodes. Mediastinal involvement was confirmed on mediastinoscopy with positive biopsies for metastatic NSCLC bilaterally within the paratracheal regions. 


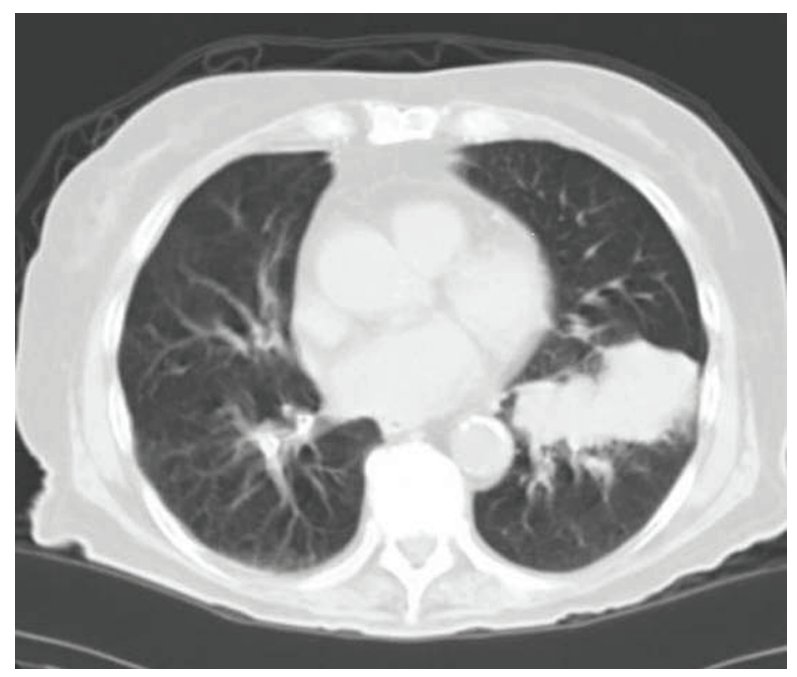

Figure 7 Staging CT scan from March 2009.

It is of note that both on CT and PET a $1 \mathrm{~cm}$ right breast mass was seen and subsequent mammography and ultrasound-guided biopsy revealed an ER/PR positive, HER-2 negative invasive ductal carcinoma, stage I (T1N0M0). Pathology was distinct from her lung and mediastinal biopsy. The remainder of her metastatic work up including MRI brain was negative.

\section{TREATMENT}

Given the results of the investigations, the conclusion was that this 83-year-old woman had a stage IIIB NSCLC (T2N3M0) with a co-existing stage 1 ductal carcinoma of the right breast. Given the extensive nodal involvement, the toxicity of an aggressive radiation or combined chemoradiation approach, low rates of cure in patients with IIIB lung cancer and patient preferences, an observant approach was agreed on. In view of her lack of symptoms, palliative radiation was not indicated, and she was not interested in pursuing palliative chemotherapy. In view of her advanced lung cancer that was thought to be the more life-threatening malignancy, no treatment for her early stage breast cancer was initiated either. The patient decided to pursue an alternative herbal remedy, and started taking Essiac tea in September 2009, and continues this, with one serving (4 oz) daily.

\section{OUTCOME AND FOLLOW-UP}

The patient continues to be seen in both medical and radiation oncology follow-up clinics every 3 months. Imaging in June 2009 showed regression of her left lower lobe tumour and this has continued to the time of publication. Figures 3-6 shows serial chest x-rays performed in April 2009, June 2009, September 2009 and March 2010, respectively. Figure 7 shows the CT part of her PET scan during her staging investigations in March 2009 and figure 8 shows the subsequent reduction of the left lower lobe mass to $2 \times 4.5 \mathrm{~cm}$ in December 2009 (lung windows). Figures 9 and 10 are analogous to figures 7 and 8 , but the mediastinal windows better demonstrate the resolution of the hilar lymphadenopathy. The patient remains asymptomatic clinically, and given the improvement seen on imaging of

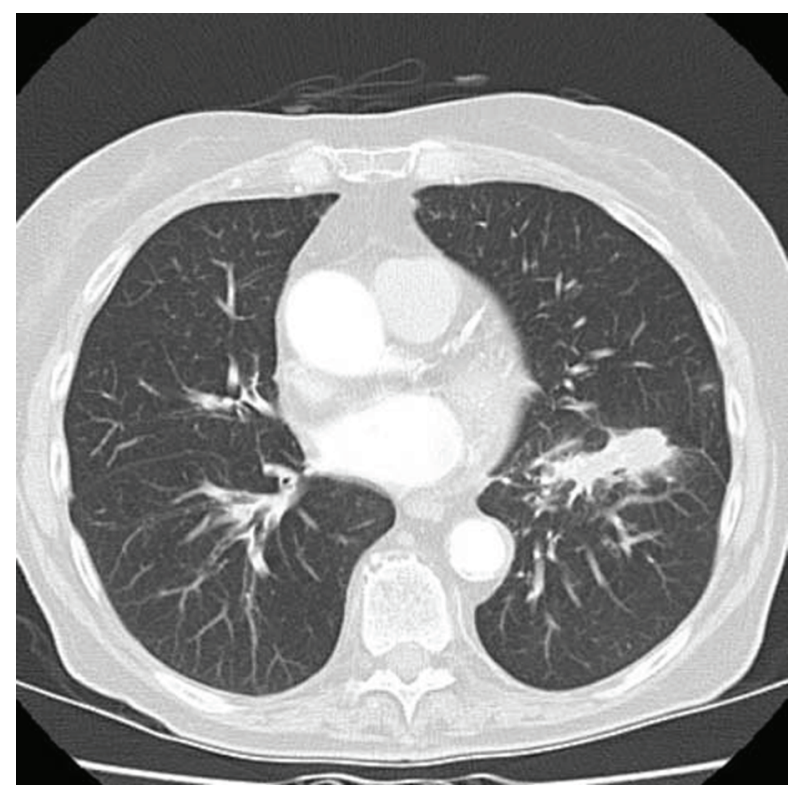

Figure 8 Image from CT scan taken in December 2009 showing reduction in the left lower lobe mass.

her lung cancer, Arimidex (an aromatase inhibitor) was started in February 2010 as a hormonal treatment for her breast cancer. Shrinkage of the lung tumour started before Essiac, and well before Arimidex.

\section{DISCUSSION}

Spontaneous regression of proven cancer was defined by Everson and Cole in 1966 as a complete or partial, temporary or permanent disappearance of all or at least some relevant parameters of a soundly diagnosed malignant disease without any medical treatment or in the presence of therapy which is considered inadequate to produce the resulting regression. ${ }^{5} 6$ Estimates put the rate of spontaneous regression at approximately 1 in 60 000-100 000 people with cancer; two thirds of these occur in malignant melanoma, renal cell cancer, non-Hodgkin's lymphoma, chronic lymphocytic leukaemia and neuroblastoma in children. Our literature review revealed only 11 reported cases of spontaneous regression in advanced stage (III-IV) NSCLC from 1950 to 2004. Of these the majority (7/11) were found to be squamous cell on histology. All seven patients were male, with a median age of 59 years (range 37-63), with confirmed spontaneous regression by serial imaging/bronchoscopy in four cases and autopsy in three cases. Mean duration of follow-up is 8.6 years (range 2-15). ${ }^{67}$

There are several theories on the potential mechanisms responsible for spontaneous cancer regression. These include the following.

\section{Modulated immunological response following systemic infection}

Immunological response is thought to be related to local cytokine release and/or cellular immune activation resulting in inflammatory necrosis or T cell-mediated apoptosis. Cytokines released in the context of viral infections (eg, measles, herpes zoster and hepatitis) have been theorised 


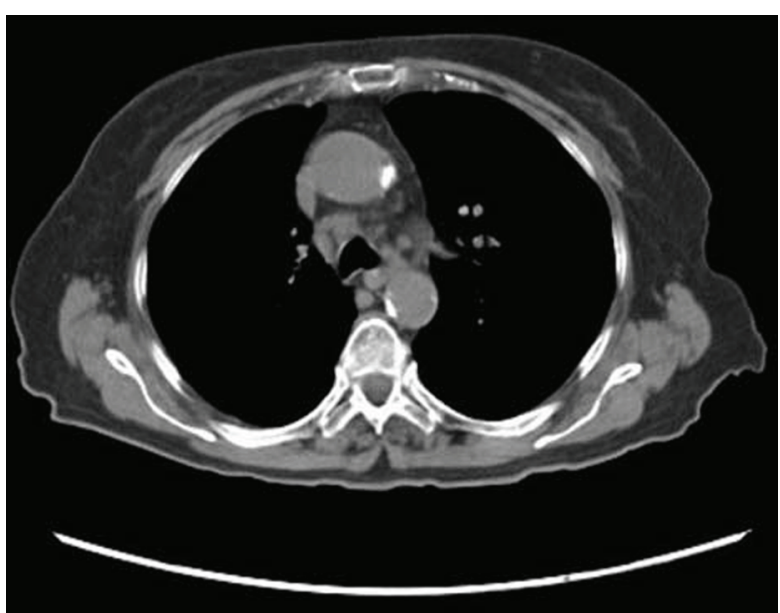

Figure 9 Mediastinal window of CT scan from March 2009 showing nodal disease.

to be linked to spontaneous regression in several case reports, mostly in non-Hodgkin's lymphoma. ${ }^{8}$ Cellular related spontaneous regression has been linked to acute myelogenous leukaemia (AML) in previous case reports, in relation to severe pneumonia and other bacterial infection. ${ }^{10}$ In general, immunological mechanisms of spontaneous regression are mainly linked to haematological malignancy rather than solid cancers. Our patient did not have any significant systemic infections throughout the time period pertinent to this case.

\section{Differentiation from normal to malignant back to normal}

Differentiation mechanisms relate to transformation of early stage (or premalignant) cells back to normal cells, usually thought to be due to cell repair in the context of removal of previously present carcinogens. ${ }^{11}$ They have mainly been reported in either germ cell tumours or in preinvasive tumours, and to our knowledge none have been reported in late stage NSCLC.

\section{Hormonal mechanisms}

In terms of hormonal mechanisms of spontaneous regression, recent studies have shown the presence of oestrogen receptors in some lung cancers, predominately adenocarcinomas, with one case report showing enlarging lung nodules after commencement of hormone-replacement therapy and subsequent regression 6 weeks after discontinuation. ${ }^{12} 13$ The patient in our case did not begin hormone therapy for her co-existing breast cancer until 6 months after regression of her lung cancer was first seen radiologically, so this is not a likely explanation for the regression of her cancer.

\section{Psychoneuroimmunological mechanisms}

Psychoneuroimmunological mechanisms have long been discussed in the context of cures associated with strong beliefs both with and without a religious philosophy.

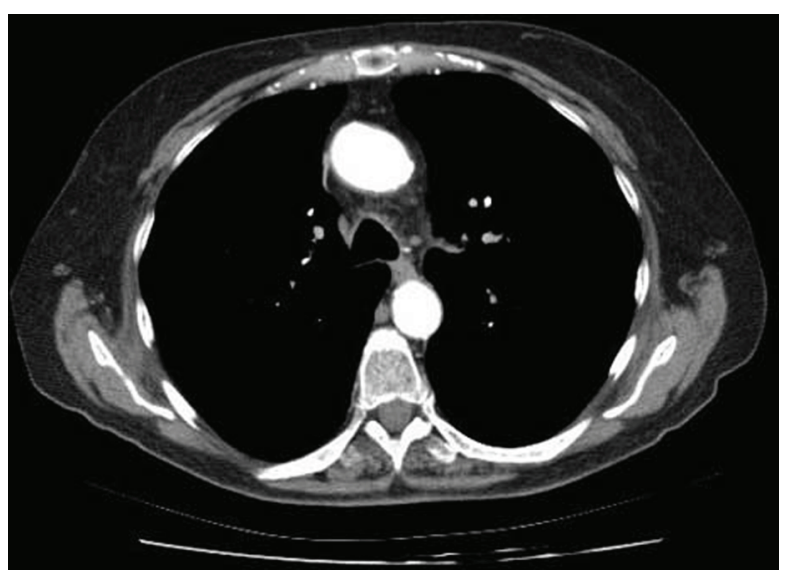

Figure 10 Mediastinal window of CT scan from December 2009 showing reduction in mediastinal lymphadenopathy.

Current theories suggest that increased psychosocial stressors can impact on cytokines such as interferon- $\boldsymbol{\nabla}$ and interleukin-2, subsequently reducing natural killer cell and lymphocyte-activated killer cell cytotoxicity. ${ }^{14}$ The theory suggests that positive thinking and reduced internal stress and anxiety can improve the body's natural defences and perhaps cause remission in some cases. Studies have examined the effect of weekly supportive group therapy sessions on overall survival in metastatic breast cancer with mixed results, and no definitive answers have yet been found. ${ }^{15} 16$ In terms of spontaneous regression of cancers, psychoneuroimmunological cases are notoriously hard to both prove and disprove, and thus are always going to feature in discussions of spontaneous regression. ${ }^{17}$

Another possible explanation is that the regression was related to the alternative herbal remedy Essiac that the patient was taking. Essiac is a combination product of four herbs (burdock root, sheep sorrel, slippery elm bark and Turkey rhubarb), although the exact formulation is a proprietary secret. Proponents of Essiac claim that it strengthens the immune system, relieves pain and may reduce tumour size and prolong the lives of people with all types of cancer; however, multiple scientific investigations have yet to yield any evidence for any of these effects. ${ }^{18}$ It should also be noted that this patient had already shown radiological improvement of her tumour at the time of starting this preparation (radiological improvement was first noted June 2009, while she started taking Essiac in September 2009).

In summary, spontaneous remission of cancer is a rare event, and even rarer in the context of advanced NSCLC. Our patient demonstrates progressive improvement on repeated radiological imaging more than 12 months after diagnosis, after evidence of relatively rapid worsening of biopsy-proven locally advanced lung cancer, and remains well, without a clear explanation for her clinical course. To our knowledge this is the first documented case of spontaneous regression of an advanced squamous NSCLC in a female patient, or in a patient over the age of 65 . 


\section{BMJ Case Reports}

\section{Learning points}

- This case demonstrates that it is very difficult to predict clinical course, even in common malignancies, and even with evidence of prior radiological progression.

- Rare occurrences of spontaneous regressions can be seen.

- Clinicians ought to be aware of uncertainties and variable clinical course when discussing prognosis.

Competing interests None

Patient consent Obtained.

\section{REFERENCES}

1 Global Burden of Disease: Update 2004. Lyon, France: IARC Press, World Health Organization, 2008.

2 Doll R, Hill AB. Smoking and carcinoma of the lung: preliminary report. $\mathrm{Br}$ Med J 1950;2:739-48.

3 Mountain CF. Revisions in the International System for Staging Lung Cancer. Chest 1997:111:1710-17.

4 NSCLC Meta-Analyses Collaborative Group. Chemotherapy in addition to supportive care improves survival in advanced non-small-cell lung cancer: a systematic review and meta-analysis of individual patient data from 16 randomized controlled trials. J Clin Oncol 2008;26:4617.

5 Everson TC, Cole WH. Spontaneous Regression of Cancer. Philadelphia, PA WB Saunders 1966
6 Cole WH. Efforts to explain spontaneous regression of cancer. J Surg Oncol 1981:17:201-9.

7 Cafferata MA, Chiaramondia M, Monetti F, et al. Complete spontaneous remission of non-small-cell lung cancer: a case report. Lung Cancer 2004:45:263-6.

8 Kumamoto M, Nakamine H, Hara T, et al. Spontaneous complete regression of high grade non-Hodgkin's lymphoma. Morphologic, immunohistochemical, and gene amplification analyses. Cancer 1994;74:3023-8.

9 Drobyski WR, Qazi R. Spontaneous regression in non-Hodgkin's lymphoma: clinical and pathogenetic considerations. Am J Hematol 1989;31:138-41.

10 Ifrah N, James JM, Viguie F, et al. Spontaneous remission in adult acute leukemia. Cancer 1985;56:1187-90.

11 Stoll BA. Spontaneous regression of cancer: new insights. Biotherapy 1992;4:23-30.

12 Kaegi E. Unconventional therapies for cancer: 1. Essiac. The Task Force on Alternative Therapies of the Canadian Breast Cancer Research Initiative. CMAJ 1998;158:897-902.

13 Wang PH, Wang HC, Tsai CC. Estrogen replacement in female lung cancer during gefitinib therapy. Jpn J Clin Oncol 2009;39:829-32.

14 Kiecolt-Glaser JK, Robles TF, Loving TJ, et al. Psycho-oncology and caner: psychoneuroimmunology and cancer. Eur Soc Med Onc. 2002;10:165-9.

15 Spiegel D, Bloom JR, Kraemer HC, et al. Effect of psychosocial treatment on survival of patients with metastatic breast cancer. Lancet 1989:2:888-91.

16 Goodwin PJ, Leszcz M, Ennis M, et al. The effect of group psychosocial support on survival in metastatic breast cancer. N Engl J Med 2001:345:1719-26.

17 Berland W. Can the self affect the course of cancer? Unexpected cancer recovery: why patients believe they survive. Advances 1995;11:5-19.

18 Ulbricht C, Weissner W, Hashmi S, et al. Essiac: systematic review by the natural standard research collaboration. J Soc Integr Oncol 2009:7:73-80

This pdf has been created automatically from the final edited text and images.

Copyright 2010 BMJ Publishing Group. All rights reserved. For permission to reuse any of this content visit http://group.bmj.com/group/rights-licensing/permissions.

BMJ Case Report Fellows may re-use this article for personal use and teaching without any further permission.

Please cite this article as follows (you will need to access the article online to obtain the date of publication).

Gladwish A, Clarke K, Bezjak A. Spontaneous regression in advanced non-small cell lung cancer. BMJ Case Reports 2010;10.1136/bcr.07.2010.3147, date of publication

Become a Fellow of BMJ Case Reports today and you can

- Submit as many cases as you like

- Enjoy fast sympathetic peer review and rapid publication of accepted articles

- Access all the published articles

- Re-use any of the published material for personal use and teaching without further permission

For information on Institutional Fellowships contact consortiasales@bmjgroup.com

Visit casereports.bmj.com for more articles like this and to become a Fellow 